\title{
Alcohol Use Patterns and Acculturation Among Chinese Students in American Universities
}

\author{
Shuangshuang Cai ${ }^{1, *}$ \\ ${ }^{1}$ Jianghan University, Wuhan, 430056, China \\ *Corresponding author. Email: zhumodanqing@126.com
}

\begin{abstract}
This research explores the relationship between alcohol use patterns and acculturation among Chinese students who studied at American Universities. A sample of 91 students participated in the study. This study used measures that included the General Ethnicity Questionnaire (GEQ) and the Alcohol Use Questionnaire. The results showed that gender and age were significant predictors of acculturation among Chinese international students. Younger Chinese students are more likely to be assimilated by American culture than those who were older. Men are more likely to be assimilated than women. Those who are more acculturated are more likely to drink alcohol than not to drink alcohol.
\end{abstract}

Keywords: Acculturation, Alcohol Consumption, Chinese International Students

\section{INTRODUCTION}

Different cultures have different alcohol-drinking patterns. For example, alcohol plays a crucial role in business and communication in China. Chinese view alcohol as the embodiment of auspiciousness and a representation of happiness [1]. Having alcoholic beverages is a way to facilitate interpersonal communication and show respect to families [2]. In American culture, drinking alcoholic beverages is an integral component of social and business life. Numerous social activities usually accompany the alcohol drinking experience.

Acculturation occurs when individuals are exposed to culturally different people, groups, and societies [3]. Nowadays, more and more Chinese students come to study in the United States. These students generally have lived in China for a long time and need to adapt to a new environment. Much research has shown that people's alcohol use behavior is influenced by transformations in the cultural environment [4]. Thus, the acculturation process may affect the evolution of the alcohol drinking behavior of Chinese students.

\subsection{Alcohol Consumption}

Previous studies have explored alcohol use patterns in both China and the United States, especially in university settings. In China, alcohol consumption appears to be controlled by traditions, economics, social pressures, and culture rather than by the government [1]. In the United States, the minimum legal drinking age is 21 , but only a few areas have age restrictions on purchasing alcoholic beverages in China. The "China Youth Risk Behavior Survey" found that almost half of Chinese university students were current drinkers, and one-fourth of them were binge drinkers [5]. In the United States, university students have been identified as a high-risk group for addiction of alcohol use. Alcohol use was associated with many health problems and adverse social consequences [6]. Comparing the alcohol use data in the WHO report, Chinese consume less alcohol per capita than Americans every year. American drinkers have higher bingedrinking rates than Chinese drinkers [7].

\subsection{Acculturation}

Acculturation is the process by which groups of individuals with different cultures come into continuous, first-hand contact with changes that have occurred successively in either one or both groups [8]. Another scholar defined acculturation as transformations that occur because of the contact with culturally dissimilar social impacts, people, and groups as applied to individuals [3].

A relatively large number of studies have looked at Latinos, Hispanic Americans, and Mexican Americans for related topics. However, there are only a few focused on Chinese students who study in American Universities. Some studies have identified acculturation as a risk factor 
for Asian American drinking behavior [9]. Others did not find significant results [10]. Length of residence, gender, place of birth, previous education, and some other variables may influence the interaction of acculturation and alcohol consumption [11][12].

\subsection{Purpose Statement}

This research aimed to examine the potential interactions between alcohol use patterns and acculturation among Chinese students who studied in American Universities. The central question is that "Does acculturation process play a causal role in the alcohol use patterns?" The following two questions were raised to support the main question: 1) What are the major alcohol use behavior among these Chinese international students? and 2) How is their assimilation to American culture related to their alcohol use patterns?

\section{METHODS}

\subsection{Participants}

Ninety-one Chinese students from an American Midwest university participated in the study. The participants met the following criteria

1) they should be Chinese international students;

2) their mother language was Chinese;

3) they should speak proficient English as their second language; and

4) they should have been informed of the background, the design, the procedure, and other information of this study.

After data cleaning, survey data from six participants were excluded from the data analysis. The reason was that there were numerous missing values in the alcohol consumption section, the demographic information section, and the acculturation section from the survey. Forty-three $(50.6 \%)$ of the remaining participants were females, and forty-two $(49.4 \%)$ were males. The youngest student was 18 years-old, and the oldest student was 39 years old (mean $=24.09$ years old, $S D=4.30$ years old). The length of residence of all these subjects varied from one month to eighty-four months (mean=30.92 month, SD=19.94 months). Forty-eight (56.47\%) participants were undergraduates, and thirty-seven $(43.53 \%)$ were graduate students.

\subsection{Measures}

2.2.1. Drinking Frequency. The self-report questions about alcohol drinking frequency in last year and the past thirty days measure their current alcohol use frequency. The self-report questions about how frequently they drunk when they were in China measure their previous alcohol use frequency. Subjects were categorized as nondrinkers and drinkers [13].

2.2.2. Acculturation. This study used a 38 -items scale called the General Ethnicity Questionnaire-Chinese Version (GEQ-C), which inquired participants to rate on their involvement in the Chinese context and attitudes toward Chinese culture. A mirroring American Version (GEQ-A) was a 38-items scale that inquired participants to rate on their involvement in the American context and attitudes towards American culture. Participants may rate them on a 5-point Likert scale. The internal reliabilities for both scales were relatively high in the original research $(\alpha=.92$ for the GEQ-C and $\alpha=.92$ for the GEQA).

\subsection{Procedures}

This research obtained the approval from the Institutional Review Board (IRB). Once approved, the investigators began to target specific populations and recruit potential participants. Students received recruitment letters and accessed the survey by opening the link of the Qualtrics website anywhere and anytime they wanted on their computers or cell-phones or iPads. If participants agree to an online informed consent form, they will sign a digital signature and then finished the questions.

All participants took 10 to 20 minutes to complete the entire questionnaire. The investigators shut down the online survey portal and downloaded data from Qualtrics after 91 participants complete the survey. The investigators used SPSS 22.0 and applied descriptive statistical analysis, crosstabs, a t-test, a chi-square test, and binary logistic regression to examine the relationships between acculturation and alcohol use patterns.

\section{RESULTS}

\subsection{Alcohol Use Patterns}

Fifty Chinese international students $(58.8 \%)$ were current non-drinkers among all participants, and thirtyfive of them $(41.2 \%)$ were current drinkers. Forty-four $(51.8 \%)$ Chinese international students were former nondrinkers, and forty-one (48.2\%) of them were former drinkers before they moved to the United States. Thirtytwo $(37.6 \%)$ students were consistent non-drinkers who never drunk alcohol in China and the United States. Twenty-three students were consistent drinkers who consumed alcohol in both countries. Twelve students changed their drinking behavior from drinkers to nondrinker after immigrating from China to the United States. On the other hand, eighteen students changed their drinking pattern from non-drinker to drinkers after entering the United States from China. Specific data is displayed in Table 1 and Table 2. 
Table 1. Drinking Frequency

\begin{tabular}{lcclcc}
\hline & \multicolumn{2}{c}{ Non-drinkers } & & \multicolumn{2}{c}{ Drinkers } \\
\cline { 2 - 3 } \cline { 5 - 6 } & $\mathrm{N}$ & $\%$ & & $\mathrm{~N}$ & $\%$ \\
\hline $\begin{array}{l}\text { Current drinking } \\
\text { frequency }\end{array}$ & 50 & 58.8 & & 35 & 41.2 \\
\hline $\begin{array}{l}\text { Previous drinking } \\
\text { frequency }\end{array}$ & 44 & 51.8 & & 41 & 48.2 \\
\hline
\end{tabular}

Table 2. Changes in Drinking Frequency

\begin{tabular}{lcc}
\hline & $\mathrm{N}$ & $\%$ \\
\hline Consistent non-drinkers & 32 & 37.6 \\
Consistent drinkers & 23 & 27.1 \\
From drinker to non-drinker & 12 & 14.1 \\
From non-drinker to drinker & 18 & 21.2 \\
\hline
\end{tabular}

The study used chi-square analysis to examine the relationship between gender and alcohol use patterns. No statistically significant chi-square result was found between contemporary alcohol drinking patterns and the gender ( $\chi 2=.017$ with $d f=1$ and $p=.897$ ). There was also no statistically significant chi-square result between the former alcohol drinking patterns and gender $(\chi 2=.104$ with $d f=1$ and $p=.748$ ). In addition, this study found no significant effect between gender and evolution in alcohol drinking patterns $(\chi 2=2.060$ with $d f=3$ and $p=.560)$.

The investigator conducted an independent-samples ttest to compare two drinking patterns for their ages. Results showed that contemporary non-drinkers $(\mathrm{M}=$ $22.19, \mathrm{SD}=3.34)$ were significantly younger than contemporary drinkers $(\mathrm{M}=25.56, \mathrm{SD}=4.41)$; $\mathrm{t}(83)=-$ $3.87, \mathrm{p}<0.001$. Results showed that former non-drinkers $(\mathrm{M}=22.19, \mathrm{SD}=3.34)$ were significantly younger than former drinkers $(\mathrm{M}=22.56, \mathrm{SD}=3.46) ; \mathrm{t}(81)=-2.40, p$ $=0.02$, when considering their alcohol drinking pattern in China. The researcher conducted multinomial regression to examine the transformation of alcohol drinking patterns by age. However, the result showed that the model did not fit significantly (chi-square $=2.09, p=0.55$ ).

The investigator was also interested in comparing the length of residence in the United States for non-drinkers and drinkers, and conducted an independent-sample ttest. Results showed that contemporary drinkers $(\mathrm{M}=$ $36.60, \mathrm{SD}=20.89$ ) resided for a more extended time in the United States than contemporary non-drinkers $(\mathrm{M}=$ 26.95, $\mathrm{SD}=18.47) ; \mathrm{t}(83)=-2.25, p=0.03)$. The researcher conducted multinomial regression to examine the transformation of alcohol drinking patterns by the length of residence. The results indicated that a one-unit increase of the drinking frequency is associated with a decrease of 2.43-months residence in the United States $(\chi 2=8.96, p=0.03)$.

\subsection{Acculturation}

The GEQ-C scale measures how substantial was the cultural orientation towards Chinese culture for participants. The study conducted an exploratory factor analysis to identify the underlying relationships between measured variables. The EFA yielded three factorloadings. For example, a 5-items factor called the "Chinese social affiliation" $(\alpha=.893)$ is individuals' demand to feel a sense of engagement and "belonging" within the Chinese cultural group. A 4-items factor called the "Chinese media" $(\alpha=.881)$ is individuals' language preference for Chinese media. The 3-items factor called the "pride of Chinese culture" $(\alpha=.792)$ is individuals' sense of national pride in Chinese culture.

The GEQ-A scale measures how substantial was the acculturation towards American culture for participants. The study conducted an exploratory factor analysis to identify the underlying relationships between measured variables. The EFA yielded four factor-loadings. A 4items factor called the "American social affiliation" $(\alpha=$ .910 ) is people's demand to feel a sense of engagement and "belonging" within the American cultural group. A 3items factor called the "American activities" $(\alpha=.891)$ is students' involvement in American events and activities. A 4-items factor called the "American language" $(\alpha=.932)$ is students' proficiency and frequency of using English as the favoured language. In addition, a 3-items factor called the "American media" $(\alpha=.888)$ is people's preference for American media such as American literature, film, and television.

This study used a binary logistic regression to predict contemporary alcohol drinking frequency from American social affiliation. Results found that a full model test against a constant-only model was statistically significant, which indicated that American social affiliation, as a factor, reliably distinguished between non-drinkers and drinkers $(\chi 2=6.299, p<.05$ with $\mathrm{df}=1)$.

The investigator conducted an independent-samples ttest to compare the scores of four acculturation factors between female students and male students. The results found significant differences were in scores of American social affiliations for females $(\mathrm{M}=1.976, \mathrm{SD}=.747)$ and males $(\mathrm{M}=2.974, \mathrm{SD}=1.281), \mathrm{t}(79)=4.322, p<.001)$. The results meant that females scored significantly lower in American social affiliation than males. Moreover, the results found a significant difference in the scores of American activities for females $(\mathrm{M}=3.830, \mathrm{SD}=.729)$ and males $(\mathrm{M}=4.183, \mathrm{SD}=.560), \mathrm{t}(81)=2.468, p<.05$. This result indicated that males scored significantly higher in participating in American events and activities than females. 


\subsection{Relationship between alcohol drinking pattern and acculturation}

A simple linear regression was calculated to predict Chinese students' engagement in American media based on age. A significant regression equation was found $(\mathrm{F}(1$, $78)=4.540, \mathrm{p}=0.036$ ), with an $R^{2}$ of 0.055 . The results showed that students' American media use decreased while their age increased. To predict English language use frequency and proficiency based on length of residence in the United States, the investigator conducted a simple linear regression. A significant regression equation was found $(\mathrm{F}(1,78)=8.909, p=0.004)$, with an $R^{2}$ of 0.103 . The result indicated that students' English language use increased while the length of residence in the United States rose.

The study conducted multiple linear regression to predict acculturation based on age, gender, and length of residence in the United States. The model found a significant regression equation $(\mathrm{F}(3,75)=5.028, \mathrm{p}=$ .003 ), with an R2 of 0.167 for predicting American social affiliation. However, the length of residence in the United States does not contribute to this model. This model is presented in Table 3 and Figure 1.

Table 3. Social Affiliation Model $(\mathrm{N}=80)$

\begin{tabular}{lccc}
\hline Variable & B & SE B & $\beta$ \\
\hline Constant & 5.247 & .748 & \\
Gender & -.980 & .232 & $-.429^{* * *}$ \\
Age & -.063 & .029 & $-.236^{*}$ \\
$\begin{array}{l}\text { Length of Stay } \\
\text { in the U.S. }\end{array}$ & .086 & .055 & .111 \\
\end{tabular}

Note. $R^{2}=.237 .{ }^{*} p<.05 .{ }^{* *} p<.01 .{ }^{* * *} p<.001$.

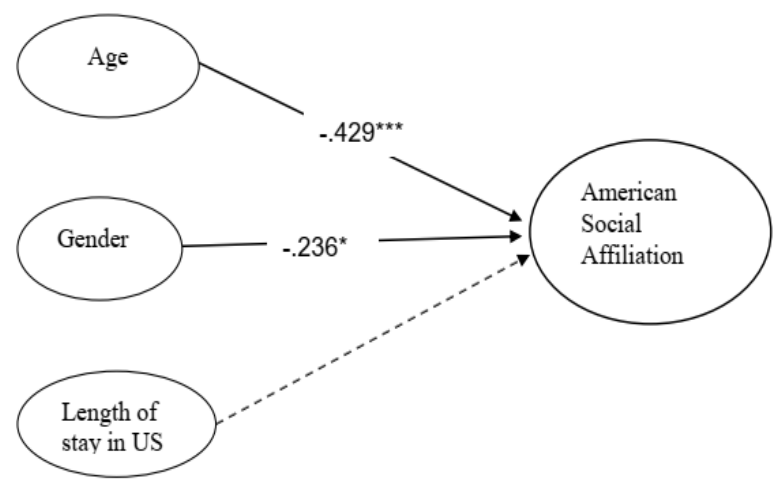

Figure 1 Social Affiliation Model $(\mathrm{N}=80)$

A significant regression equation was found $(\mathrm{F}(3$, 76) $=3.023, \mathrm{p}=.035$ ), with an $\mathrm{R} 2$ of .107 for predicting American language use. However, gender and age did not contribute to this model. This model is presented in Table 4 and Figure 2.
Table 4. Language Model (N=79)

\begin{tabular}{lccc}
\hline Variable & B & SE B & $\beta$ \\
\hline Constant & 3.666 & .487 & \\
Gender & -.036 & .150 & -.027 \\
Age & -.010 & .019 & -.064 \\
$\begin{array}{l}\text { Length of Stay } \\
\text { in the U.S. }\end{array}$ & .012 & .004 & $.342^{* *}$ \\
\hline
\end{tabular}

Note. $R^{2}=.107 .{ }^{*} p<.05 .{ }^{* *} p<.01 .{ }^{* * *} p<.001$.

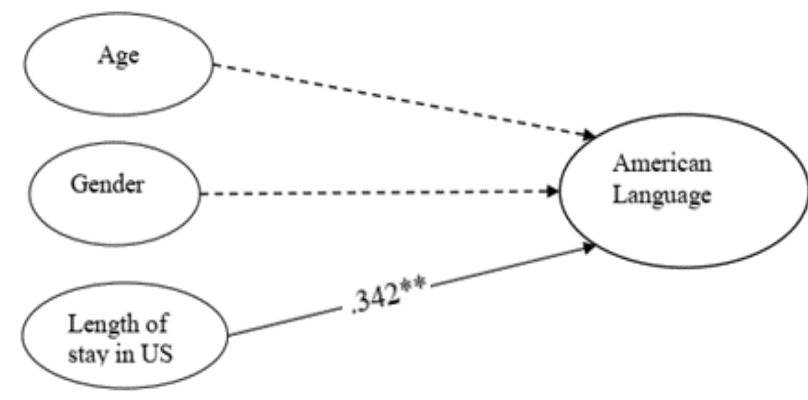

Figure 2 Language Model (N=79)

\section{DISCUSSION}

More than half $(58.8 \%)$ of Chinese international students studying in American Universities were currently non-drinkers. This result is similar to Chinese students studying in Chinese universities (Jin, 2015). Most (64.7\%) Chinese international students remain their past alcohol drinking patterns while $35.3 \%$ of them made some changes. Length of residence, age, and gender were significant predictors of alcohol-drinking patterns. For example, non-drinkers were significantly younger than drinkers. Drinkers reside considerably longer in the United States than non-drinkers. The longer individuals lived in the United States; former non-drinkers were more likely to drink alcohol rather than remain not drinking alcohol at all. An explanation for these results is that when individuals reside longer in the United States, they are more likely to reach the legal minimum drinking age and consume alcohol.

Females were less possibly to acculturate with American culture than males. Females were also less possibly to take part in American events and activities than males. Younger Chinese students in American Universities were more likely to read literature, view films and televisions, or listen to radios in English. An explanation is that undergraduate students were younger and they usually lived on-campus. They had more opportunities to interact with their American peers and were more likely to be exposed to American adventures and media. On the other hand, elder students were usually graduate students, and they regularly lived off-campus. They had more opportunities to interact with and associated more exclusively with their Chinese peers. 
Results also showed that the longer they reside in the United States, the more they would possibly utilize English as their preferred language to communicate with others. The interpretation of this result is that students' English skills will be better because they may encounter more chances and situations to interact with English speakers. Younger Chinese students are more likely to assimilate into American culture because they might be more open-minded. Another possible explanation is that elder ones lived longer in China and had a higher degree of heritage-culture retention than their younger peers.

\section{CONCLUSION}

The study adds to the literature on the potential acculturation effects for Chinese students who studied in the United States regarding their alcohol use patterns. There were some limitations to the research. First, the sample size is too small. Only 91 students participated in the study. Secondly, the participants were asked to recall their alcohol consumption experience when they were in China. Thus, there were systematic errors of recall bias caused by distinctions in the subjects' accuracy of the memories regarding their former alcohol use activities.

As there were a few studies on this topic, and the issues about alcohol addiction and alcohol abuse are constantly emerging, the results have some guiding significance and application value for related research. It is also helpful to understand the acculturation effect in the cultural interaction across Chinese and American contexts more comprehensively. In future research, the researchers will apply a bidimensional model that describes the acculturation process as assimilation, separation, integration, and marginalization. The investigator will interview Chinese students in American Universities about their specific living experience of studying abroad, primarily focus on their alcohol drinking activities and their attitudes towards acculturation.

\section{REFERENCES}

[1] I. Newman, "Cultural aspects of drinking patterns and alcohol controls in China," The Globe (Global Alcohol Policy Alliance, London), no. 1, pp. 18-21, 2002.

[2] M. Martinic and F. Measham, Swimming with crocodiles: The culture of extreme drinking. Routledge, 2008.

[3] M. A. Gibson, "Immigrant adaptation and patterns of acculturation," Human development, vol. 44, no. 1, pp. 19-23, 2001.

[4] J. Xue and X. Fang, "Wen hua ding wei yu gao zhong sheng yin jiu xing wei zhi jian de guan xi [Cultural orientation and Chinese adolescent drinking]," Zhong Guo Xing Wei Yi Xue Za Zhi
[Chinese Journal of Behavioural Medical Science], vol. 14, no. 11, pp. 1019-1020, 2005.

[5] C. Y. Ji, P. J. Hu, and Y. Song, "The epidemiology of alcohol consumption and misuse among Chinese college students," Alcohol and Alcoholism, vol. 47, no. 4, pp. 464-472, 2012.

[6] National Institute on Alcohol Abuse and Alcoholism, "NIAAA council approves definition of binge drinking," NIAAA newsletter, vol. 3, no. 3, p. 3, 2004.

[7] Geneva: World Health Organization, Global Status Report on Alcohol and Health 2018.

[8] R. Redfield, R. Linton, and M. J. Herskovits, "Memorandum for the study of acculturation," American anthropologist, vol. 38, no. 1, pp. 149$152,1936$.

[9] C. S. Hendershot, L. MacPherson, M. G. Myers, L. G. Carr, and T. L. Wall, "Psychosocial, cultural and genetic influences on alcohol use in Asian American youth.," J. Stud. Alcohol, vol. 66, no. 2, pp. 185195, Mar. 2005, doi: 10.15288/jsa.2005.66.185.

[10] C. S. Hendershot, T. M. Dillworth, C. Neighbors, and W. H. George, "Differential effects of acculturation on drinking behavior in Chinese-and Korean-American college students," Journal of Studies on Alcohol and Drugs, vol. 69, no. 1, pp. 121-128, 2008.

[11] J. C. Gfroerer and L. L. Tan, "Substance use among foreign-born youths in the United States: does the length of residence matter?," American Journal of Public Health, vol. 93, no. 11, pp. 1892-1895, 2003.

[12] C. Lum, H. Corliss, V. M. Mays, S. D. Cochran, and C. K. Lui, "Differences in the Drinking Behaviors of Chinese, Filipino, Korean, and Vietnamese College Students," Journal of Studies on Alcohol and Drugs, vol. 70, no. 4, pp. 568-574, 2009, doi: https://doi.org/10.15288/jsad.2009.70.568.

[13] D. F. Shell, I. Newman, and Q. Ming, "Alcohol Expectancies Among High School Students in Inner Mongolia, China," Asia Pacific Journal of Public Health, vol. 21, no. 4, pp. 433-441, doi: https://doi.org/10.1177/1010539509344345. 